\title{
AAVV. La Orihuela de Miguel Hernández. 1910-1942. Orihuela: Fundación Cultural Miguel Hernández, 2011, 302 pp.
}

La edición de catálogos de exposiciones puede convertirse en un aporte de primerísimo orden al conocimiento del autor al que se dediquen, y en los últimos lustros se han dado varias pruebas que corroboran este aserto, teniendo más de una a Miguel Hernández como pretexto. Aludimos al Catálogo de la Exposición "Miguel Hernández, poeta", celebrada en Alicante en 1992, a los cincuenta años de la muerte del escritor, y aludimos también a la Exposición llevada a cabo en la Biblioteca Nacional de Madrid en coincidencia con el primer centenario (2010) de su nacimiento, Exposición titulada “La sombra vencida (1910-2010)". Otro Catálogo hernandiano ha aparecido en las postrimerías de 2011, el que se corresponde con la Exposición, celebrada en los meses de noviembre y diciembre de ese año en una sala oriolana, titulada "La Orihuela de Miguel Hernández 1910-1942", un título que es el mismo que lleva el Catálogo editado por la Fundación Cultural Miguel Hernández. Este evento expositivo fue comisariado por Emilio Díaz Ardid, Aitor L. Larrabide y Víctor Sánchez Balaguer.

Bien diseñado y cuidadosamente impreso, el Catálogo comprende copiosas ilustraciones, y de tres tipos: reproducción de documentos diversos (planos y otros); portadas de libros y de publicaciones periódicas; viñetas y dibujos varios, algunos debidos al talento artístico de Miguel Hernández; y muchas fotografías, tanto individuales como de grupo, pero sobre todo urbanas de Orihuela, instantáneas gráficas éstas que ayudan a captar un tanto la atmósfera de la ciudad en los años referidos a la vida del escritor.

Precedidos por unos prolegómenos que corrieron a cargo de Juan José Sánchez Balaguer, Director de la Fundación Cultural Miguel Hernández, y de Ana Mas de Sanfélix, concejala de cultura del Ayuntamiento olecense, los textos que se han incorporado al Catálogo son mayormente atípicos en la bibliografía hernandiana, porque ninguno se centra estrictamente en la literatura del poeta, y uno solo a su vida, el de José Luis Ferris. En realidad, el Catálogo refleja el contenido de una exposición que fue concebida para documentar el contexto nativo de Miguel Hernández, abordándolo desde diferentes perspectivas: la geografía urbana, la artística y arquitectónica, la política, la periodística y revisteril, la literaria y la recepcional de su obra en la posguerra. Cuatro son los apartados en los que se han distribuido los diferentes artículos, siendo el más abundante el primero, con media docena de textos, la mitad de ellos centrados en la política e historia oriolanas hasta 1939. El segundo de los apartados se compone del citado trabajo de Ferris y de otro acerca de personajes oriolanos que se cruzaron en la vida del autor de El rayo que no cesa. Los apartados III y IV constan de sendos aportes cada uno, aportes que firman dos reconocidos expertos hernandianos: "La literatura en la Orihuela de Miguel Hernández", estudio al alimón de Luis Mariano Abad Merino y José Antonio Torregrosa Díez; y "La difusión de Miguel Hernández en Orihuela durante la posguerra", páginas debidas a Aitor L. Larrabide. A continuación vamos a pasar revista somera a las aportaciones que se recogen en cada una de estas secciones.

La sección "Historia, economía y arte" va encabezada por un trabajo de Jesús Millán, de la Universidad de Valencia, y que gira en torno a "La política oriolana en la primera etapa de Miguel (1910-1931): del colapso del liberalismo de élites al arranque de la democracia de masas". Al abarcar el contexto histórico primero del poeta, este estudio resulta indispensable para advertir los condicionantes en los que se vio envuelto hasta la llegada de la República, y en un ambiente societario que no respondía al tópico que califica de ciudad levítica a Orihuela, pues de levítica e inmóvil, al compás de la hegemonía de los liberales, tenía más bien poco por esas calendas, registrándose incluso un cierto dinamismo de aires nuevos y modernizadores en el ámbito eclesiástico, siendo el canónigo Luis Almarcha uno de los promotores de este giro renovador, a veces expresado en acciones sociales que contrarrestasen las filosofías reivindicativas de aquel tiempo. Miguel Hernández hubo de desenvolverse en ese medio a la sazón cambiante, y decidió practicar el posibilismo que aconsejaban las circunstancias.

El segundo de los artículos se debe a Antonio José Mazón Albarracín, y versa acerca de “La política oriolana entre las elecciones de 1931 y la victoria del Frente Popular en 1936”. Ahí se recrea el período histórico acotado, subrayando las transformaciones a que dio lugar la 
sustitución del régimen monárquico por el republicano. Asimismo se expone el mosaico de partidos políticos que había en la localidad, la cual contaba con unas 38.500 personas, más de la mitad de las cuales vivía en distintas zonas rurales. Encabeza el artículo una foto espléndida y emocionante por su capacidad de suscitar evocaciones plenas de veracidad: la de la Casa del Pueblo oriolana en 1931, importante espacio político de la ciudad, y cuya puerta debió cruzar Miguel Hernández en distintas oportunidades ese año. En ese verano, en efecto, e "influido por su amigo Augusto Pescador Sarget, fue nombrado presidente fundador de las Juventudes Socialistas locales" (p. 31)

El artículo centrado en "Orihuela y la guerra civil" tiene autoría doble, la de Agustín y Ricardo Castaño Martínez. Al historiar un corte cronológico tan convulso, el texto se hace eco de una Orihuela bulliciosa que ha aumentado su población acogiendo a refugiados de otras zonas, al principio procedentes de Madrid. Ahí se destaca también la habilitación de edificios para funciones militares varias, y el hecho de que la ciudad fuese sede exclusiva de la Academia de Oficiales Carabineros de España, institución a la que se emplazó en el colegio de Santo Domingo. Interesa remarcar también cómo algunas de las acciones acometidas por el régimen franquista en esos primeros tiempos vinieron a suceder a acciones similares que habían emprendido los republicanos. Estos, por ejemplo, convirtieron el Seminario de San Miguel en un campo de trabajo para prisioneros de guerra del bando contrario, y luego el nuevo régimen hizo lo propio al utilizar el edificio como cárcel, donde estuvo Miguel Hernández entre los meses de octubre y noviembre de 1939, y con anterioridad a que lo encarcelasen en la prisión madrileña de conde de Toreno. También continuaron los vencedores con la fórmula de las cartillas de racionamiento que heredaron de los vencidos, y cuya vigencia se prolongó hasta 1952. Por lo demás, da fe el artículo de que varios días antes del Parte de guerra del 1 de abril de 1939 que proclamaba el final de la contienda bélica y la derrota del Ejército de la República, Orihuela ya se dispuso a acomodarse al contexto sobrevenido, de modo que "se convirtió en la primera población alicantina que mostraba públicamente su deseo de unirse al bando nacional." $(60)$

De todas las colaboraciones insertas en el Catálogo, la que más se extiende sobre la historia oriolana, porque abarca nada menos que cien años de ella, es la que han escrito dos componentes del Grupo Interdisciplinario de Estudios Críticos y de América Latina, grupo adscrito a la Universidad de Alicante. Se trata de Gregorio Canales Martínez y de Alejandro López Pomares, coautores de "Orihuela, transformación socioeconómica de una ciudad y su territorio (1910-2010)". Trabajo sólido, y valioso para el aprecio de la evolución de la ciudad y de su entorno hasta el presente, por alcanzar hasta la década primera del siglo XXI inclusive, buena parte de él no se ocupa del contexto coetáneo de la cronología hernandiana, desbordando a mayores el enunciado a que se refiere el Catálogo. Los epígrafes que se corresponden con la vida del poeta conllevan de vez en vez útiles informaciones acerca del espacio geográfico, urbano y societario en cuyo medio vivió el escritor, con interesantes notas a propósito de la vega del Segura y de las industrias oriolanas de la época.

Amén de ser Director de la Fundación Cultural Miguel Hernández, Juan José Sánchez Balaguer figura también entre los estudiosos del hernandismo. En calidad de tal, y como miembro significado de la Cátedra Miguel Hernández de la Universidad Miguel Hernández de Elche, ha contribuido al Catálogo con el artículo "La prensa oriolana en tiempos de Miguel Hernández". En él pasa revista a todas y cada una de las publicaciones de Orihuela, la mayoría con vinculación eclesiástica, en las que publicó el poeta, consignando siempre su participación concreta en las mismas. El recorrido, de índole cronológica, lo inicia centrándose en El Pueblo de Orihuela, donde por mediación de Carlos Fenoll vio Hernández estampado un poema suyo por primera vez, y lo culmina ocupándose de la revista Silbo, donde publicaría por última vez en Orihuela, también a través de Fenoll, y no sin dedicar un epígrafe final y complementario a Memento, publicación oriolana de Semana Santa que se refirió al autor de El rayo que no cesa en una entrega aparecida el mismo día de su muerte (28 de marzo de 1942), pues en sus páginas se editaron los versos de Antonio Fantucci que integran su poema "Mane, nobiscum, domine", dedicados "A Miguel, que se muere solo".

El artículo "Arte y arquitectura en la Orihuela de Miguel Hernández (1910-1942)", del que es autor Emilio Díz Ardid, arqueólogo municipal del Ayuntamiento olecense, es el sexto y último de la sección primera del Catálogo. Como bien señala su título, el trabajo se refiere a las 
manifestaciones artísticas y arquitectónicas habidas en la ciudad desde principios del XX hasta mediados de dicha centuria, comentando la significación de los diversos artistas de las distintas artes plásticas, alguno de ellos, Francisco Díe, vinculado al poeta, y finalizando el estudio con un epílogo en el que destaca que, de la mano de Maruja Mallo, que es como decir de la del propio Miguel Hernández, y asimismo a través de Eduardo Vicente y de Ángel Ferrant, la vanguardia también llegó a Orihuela. Como apostilla diré que se echan en falta en el artículo, o así me lo parece, unas líneas al menos en torno a la segunda de las tres etapas arquitectónicas que Díz Ardid enumera al mencionar los estilos arquitectónicos de las primeras cuatro décadas del siglo pasado, etapas que, según señala, fueron tres: "modernismo, casticismo y movimiento moderno" (126)

José Luis Ferris, estudioso bien conocido de la vida de Miguel Hernández, y docente de la Universidad que lleva el nombre del poeta, contribuye al Catálogo con las páginas tituladas "Miguel Hernández. Notas para una biografía", las cuales conforman el primero de los dos textos ubicados en la sección "Personajes". El artículo es un resumen de la trayectoria vital y literaria del autor de Viento del pueblo, un resumen bien trazado por quien acaso mejor podía trazarlo, y en el que merecen subrayarse especialmente los pasajes en los que describe el progresivo distanciamiento hernandiano de la tutela sijeana, y hasta el influjo del grupo de Vallecas, y en especial del escultor Alberto Sánchez.

El segundo de los artículos de la sección segunda se debe a José Luís Galiano Pérez, quien escribe sobre "Personajes oriolanos de una comedia humana terminada en tragedia". Es este un texto singular donde los haya, sobre todo por la relectura que hace de los comportamientos de personas oriolanas que se cruzaron en la vida de Miguel Hernández, y cuyas conductas respectivas se han valorado a menudo no sólo muy negativamente, sino que incluso se las demonizó. La palma del anatema se la han llevado los dos funcionarios que lo denunciaron, a fines de septiembre de 1939, denuncia que comportaría que el poeta fuese encarcelado en el Seminario. José Luís Galiano Pérez apunta que habría que ponerse en el lugar de tales personas en aquel contexto y hacer un esfuerzo para que sus actitudes de entonces sean valoradas en función de aquellos condicionantes, no sin añadir que no estuvo tampoco Miguel Hernández siempre acertado en algunas de las decisiones que tomó.

El trabajo de Mariano Abad Merino y José Antonio Torregrosa Díaz abarca por entero la sección III del Catálogo, la titulada "Literatura". El estudio gira en torno de "La literatura en la Orihuela de Miguel Hernández", y constituye con mucha diferencia el texto más extenso de los que se recogen en el volumen. Se atiende en sus páginas a las letras oriolanas anteriores a la polémica suscitada a raíz de la publicación, en 1926, de El Obispo leproso, de Gabriel Miró, una polémica que se expone con detalle suficiente para que los lectores conozcan la importancia que tuvo, sobre los jóvenes intelectuales del momento, con vistas a que adquiriesen cabal conciencia estética de lo que podía suponer la literatura oriolana más genuina. Se ocupa igualmente este trabajo de la visita de José Zorrilla a la ciudad, una visita no menos triunfal que otras muchas que realizó a tantas ciudades españolas, y se detiene en autores de alto interés para entender mejor los comienzos literarios hernandianos, así Juan Sansano y José María Ballesteros. Bien provechosas son las reflexiones a vueltas de la algunas veces llamada generación oriolana de 1930, y asimismo de la problemática suscitada por la tahona de Fenoll como punto de encuentro de Sijé, Hernández, y obviamente del propio anfitrión, además de otros escritores en ciernes. Se admite que pueda hablarse, en relación a los citados, del grupo de Orihuela, y se pondera el positivo ascendente de Sijé sobre el autor de Perito en lunas, por quien tanto hizo, aun cuando llegó a sentirse autorizado, quizá por eso mismo, a sermonearle cuando le veía alejarse del ideario religioso y cultural con el que el joven ensayista se identificaba. Abad y Torregrosa no pasan por alto tampoco la noticia, bien documentada, de las publicaciones oriolanas vinculables al poeta, concediendo condigna espacio a El Gallo Crisis y Silbo.

El último de los estudios acogidos en el Catálogo lleva la firma de quien ha hecho del hernandismo, e incluso de su gestión institucional, una indeclinable razón de ser, siendo constantes sus contribuciones al mejor conocimiento de cuanto puede relacionarse con la vida y con la obra de Miguel Hernández. Hacemos referencia a Aitor L. Larrabide, autor de numerosos trabajos sobre el poeta, entre los cuales me parece pertinente recordar aquí un breve texto de 1997 titulado "La difusión de Miguel Hernández en la inmediata posguerra". En 2011, casi tres lustros después, ha retomado el asunto, pero ampliando su lapso cronológico a la vez que 
circunscribiendo la difusión a la ciudad natal del escritor, al ser este el marco delimitado por la exposición de cuyo libro resultante estamos dando cuenta.

El título del trabajo de Larrabide, "La difusión de Miguel Hernández durante la posguerra", queda desbordado por el contenido que se incluye en el mismo, pues alcanza y aun supera los años de la Transición política. De este desajuste, sin embargo, se benefician los lectores, porque la información que se les suministra es más copiosa, al recogerse hechos de propagación hernandista que van desde la década más inmediata a la guerra hasta rozar los ochenta. Los datos que el artículo proporciona en relación al recuerdo, desde Orihuela, de la persona y de la obra de Miguel Hernández son tan precisos como abundantes, y no cumple recogerlos aquí. Pero pondremos énfasis en que durante los años más duros, en los cuarenta, iban a ser los amigos del escritor quienes sacaron el coraje suficiente para, con las cautelas estratégicas aconsejables, hacer aflorar la memoria hernandiana, una memoria que, por parte oriolana, tampoco se ha dejado llevar por la fascinación de la leyenda ni del mito.

José María Balcells 